\title{
OCCURRENCE OF HYPEROSTOTIC PTERYGIOPHORES IN THE SILVER SCABBARDFISH, LEPIDOPUS CAUDATUS (ACTINOPTERYGII: PERCIFORMES: TRICHIURIDAE)
}

\author{
Filippo GIARRATANA*, Anna RUOLO, Daniele MUSCOLINO, Fabio MARINO, Michele \\ GALLO, and Antonio PANEBIANCO
}

Faculty of Veterinary Medicine, Polo Universitario dell'Annunziata, Messina, Italy

Giarratana F., Ruolo A., Muscolino D., Marino F., Gallo M., Panebianco A. 2012. Occurrence of hyperostotic pterygiophores in the silver scabbardfish, Lepidopus caudatus (Actinopterygii: Perciformes: Trichiuridae). Acta Ichthyol. Piscat. 42 (3): 233-237.

\begin{abstract}
Background. Hyperostosis is a productive change characterized by an increase of the periosteal ossification combined with resorption of the bony tissue. It is common in several fish species. Its presence has been reported in the silver scabbardfish, Lepidopus caudatus (Euphrasen, 1788). The aim of the presently reported study is to improve the knowledge on the presence of hyperostotic pterygiophores in L. caudatus.

Materials and methods. In total, 50 specimens of Lepidopus caudatus, captured off the coast of Messina (Sicily, Italy) were examined by radiography. Deformed pterygiophores were decalcified and processed for histopathological examination, and the sections obtained were stained with haematoxylin and eosin.

Results. Forty $(80 \%)$ of the 50 specimens examined showed skeletal deformities exclusively on the pterygiophores of the dorsal fin. In total, 433 deformities were observed. Histological examination showed slight expansion of the bone tissue, which was poor in cells and characterised by thin layers of compact bone tissue. Macroscopic, radiographic, and histological findings were consistent with diagnosis of hyperostosis.

Conclusion. Hyperostosis of $L$. caudatus does not affect its consumption. However, it may be a complication for filleting techniques as the presence of hyperostosis along the longitudinal axis of teleosts does not allow a complete and repeatable filleting technique. This could increase the possibility of bacterial contamination, loss of muscle tissue, and imperfections in cutting and trimming.
\end{abstract}

Keywords: fish osteology, histology, pterygiophore, hyperostosis, periosteal ossification, resorption of bony tissue

\section{INTRODUCTION}

Several abnormalities have been reported in natural populations of fishes (Dawson 1964, 1966, 1971, Dawson and Heal 1971). Among these hyperostosis are described as a productive change in bone tissue, characterized by an increase of the periosteal ossification combined to resorption of the bony tissue (Meunier et al. 2010). The aetiopathogenesis (causes and development of a disease or abnormal condition) and functional impact are poorly understood (Meunier et al. 2010). Hyperostosis usually appears as a thickening of specific bones that takes a swollen aspect. It is observed especially in the pterygiophores, skulls, claviculae, and haemal and neural spines of teleost fish. The pterygiophores are a series of chondral bony structures that support the dorsal and anal rayed fins. The occurrence of swollen or hyperostotic bones was identified in 92 species belonging to 22 families such as Carangidae, Sparidae, and Trichiuridae (see Smith-Vaniz et al. 1995, Smith-Vaniz and Carpenter, 2007, Rapisarda et al. 2008, Meunier et al. 2010). Several members of the family Trichiuridae often show hyperostosis on the pterygiophores (Grabda 1982, Meunier et al. 2010). In this family, the presence of hyperostosis has been a common feature of the silver scabbardfish, Lepidopus caudatus (Euphrasen, 1788), as was first reported by Gunther in 1860 (James 1960). L. caudatus is one of the most important species commercially exploited in the province of Messina (Sicily, Italy), where consumption of preparations of fresh L. caudatus, such as roulade, breaded fillets, and pies, is high.

Filleting of fish reveals some deformities of the bone tissue that are not visible on external examination. Among these, hyperostoses, which are usually located deep in the muscle tissue near the spine, are not easily identifiable by routine inspection of fish. The presence of these deformities could represent a problem during the filleting, notably in species where the frequency of these deformities is very high such as the silver scabbardfish.

In order to improve the knowledge on the presence of deformities in this species, the aim of the present paper

\footnotetext{
* Correspondence: Dr. Filippo Giarratana, Facoltà di Medicina Veterianaria, Dipartimento di Sanità Pubblica Veterinaria, Polo Universitario Annunziata, 98168 Messina, Italy, phone : +39.90.3503768, fax: +39.90.3503937, email: fgiarratana@unime.it.
} 
was to conduct a radiological and anatomopathological study on hyperostotic pterygiophores of L. caudatus.

\section{MATERIALS AND METHODS}

The presently reported study was carried out on 50 specimens of $L$. caudatus captured off the coast of Messina. Each specimen was brought to our laboratory, numbered, measured (standard length and body weight), and subjected to radiological examination. Radiographs were taken using the Raffaello Hf4 Acem apparatus. For each specimen, 2 or 3 radiographic images were necessary to visualise the length of the fish. Once the radiographs had been obtained, we proceeded to identify, count, measure, and record the skeletal deformities using eFilm Lite (TM) software (Merge eMed). In particular, the length of the major and minor axes of each deformity was measured.

Histological examination was carried out on 9 specimens with skeletal macroscopic alterations. The deformities were excised, fixed in $10 \%$ buffered formalin, decalcified with EDTA, and routinely processed for histopathology. The sections obtained were stained with haematoxylin and eosin (HE).

To evaluate the distribution of deformities, each specimen (total of 105 pterygiophores) was divided into 7 segments of 15 pterygiophores each: 1-15 (A), 16-30 (B), 31-45 (C), 46-60 (D), 61-75 (E), 76-90 (F), and 91-105 (G). For statistical analysis, all specimens were grouped in quintiles according to the following groups of number of deformities observed $(\mathrm{nD})$ : no deformities (first quintile), 1-5 deformities (second quintile), 6-8 deformities (third quintile), 9-13 deformities (fourth quintile), and more than 13 deformities (fifth quintile). Simple linear regression analysis was conducted to determine the relation between the average values of $\mathrm{nD}$ for each group and their average standard length and weight.

\section{RESULTS}

The standard length of the fish varied from 81 to $110 \mathrm{~cm}$. The mean standard length of the fish was $94.32 \mathrm{~cm}( \pm 6.98 \mathrm{~cm}$ standard deviation). These specimens had an average weight of $680.58 \mathrm{~g}$ ( $\pm 162.90 \mathrm{~g}$ standard deviation; range $430-1160 \mathrm{~g})$. Of the 50 specimens observed, 40 (80\%) had skeletal deformities exclusively on the pterygiophores of the dorsal fin. On these 40 fish, a total of 433 deformities were counted, with the average $\mathrm{nD}$ of 11 ( $\pm 9.39 \mathrm{SD})$ for each specimen (range: 1-43). No deformities were observed in the remaining 10 samples $(20 \%)$.

On the 105 pterygiophores presented in L. caudatus, these deformities were observed only from the pterygiophore No. 1 to the pterygiophore No. 86. The highest $\mathrm{nD}$ (130) was recorded in segment $\mathrm{A}$. The second highest $\mathrm{nD}$ (76) was found in segment D, followed by segment E with $68 \mathrm{nD}$. In segments $\mathrm{B}$ and C, 56 and $59 \mathrm{nD}$ were observed, respectively. Finally, 44 deformities were found on segment F. No malformations were found from the pterygiophores posterior to pterygiophore No. 87 (Fig. 1). The highest $\mathrm{nD}$ were noted on the pterygiophore No. 4 in 31 specimens (77.50\%). Seventeen specimens $(42.50 \%)$ showed deformities on the pterygiophore No.10, while pterygiophores Nos. 5 and 11 were affected in 15 specimens (37.50\%) (Fig. 2).

The deformed pterygiophores observed were oval, irregular, and round in shape, and usually they appeared compressed laterally (Fig. 3). Their radiological aspects were similar to those of the surrounding bone tissue (Fig. 4). The deformities varied in size, with the mean shortest diameter of $0.44 \mathrm{~cm}( \pm 0.18 \mathrm{~cm} \mathrm{SD}$; range, $0.20-1.00 \mathrm{~cm})$ and longest diameter of $0.66 \mathrm{~cm}( \pm 0.24 \mathrm{~cm} \mathrm{SD}$; range, $0.20-1.50 \mathrm{~cm})$. A good statistical correlation between among the fish length, weight, and $\mathrm{nD}$ was noted (Figs. 5-6).

Histological examination showed slight expansion of the bone tissue, which was poor in cells and characterised by thin layers of compact bone tissue. Optically empty spaces were limited by thin acellular trabeculae of primary compact bone (Fig. 7). Because of these relatively large spaces, the lesion appeared sponge-like. In some cases, the presence of osteoblasts was ascertained, but no osteoclasts were found.

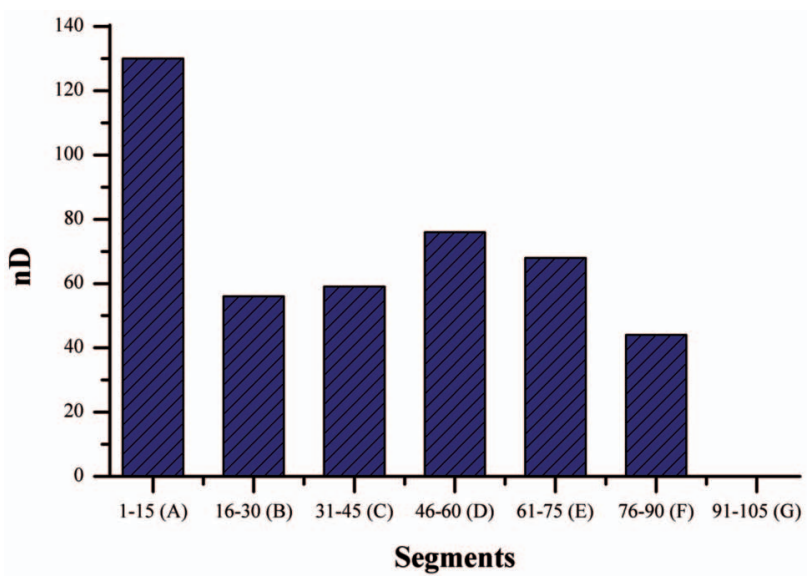

Fig. 1. Total number of deformities $(\mathrm{nD})$ for each body segment (containing 15 pterygiophores) of silver scabbardfish, Lepidopus caudatus, caught off Sicily, Italy

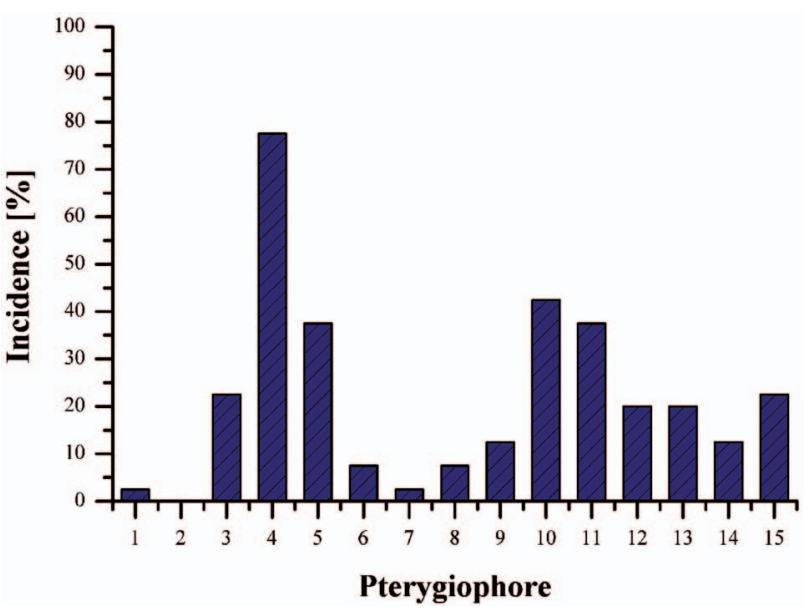

Fig. 2. Incidence of deformities on pterygiophores of segment A of silver scabbardfish, Lepidopus caudatus, caught off Sicily, Italy 


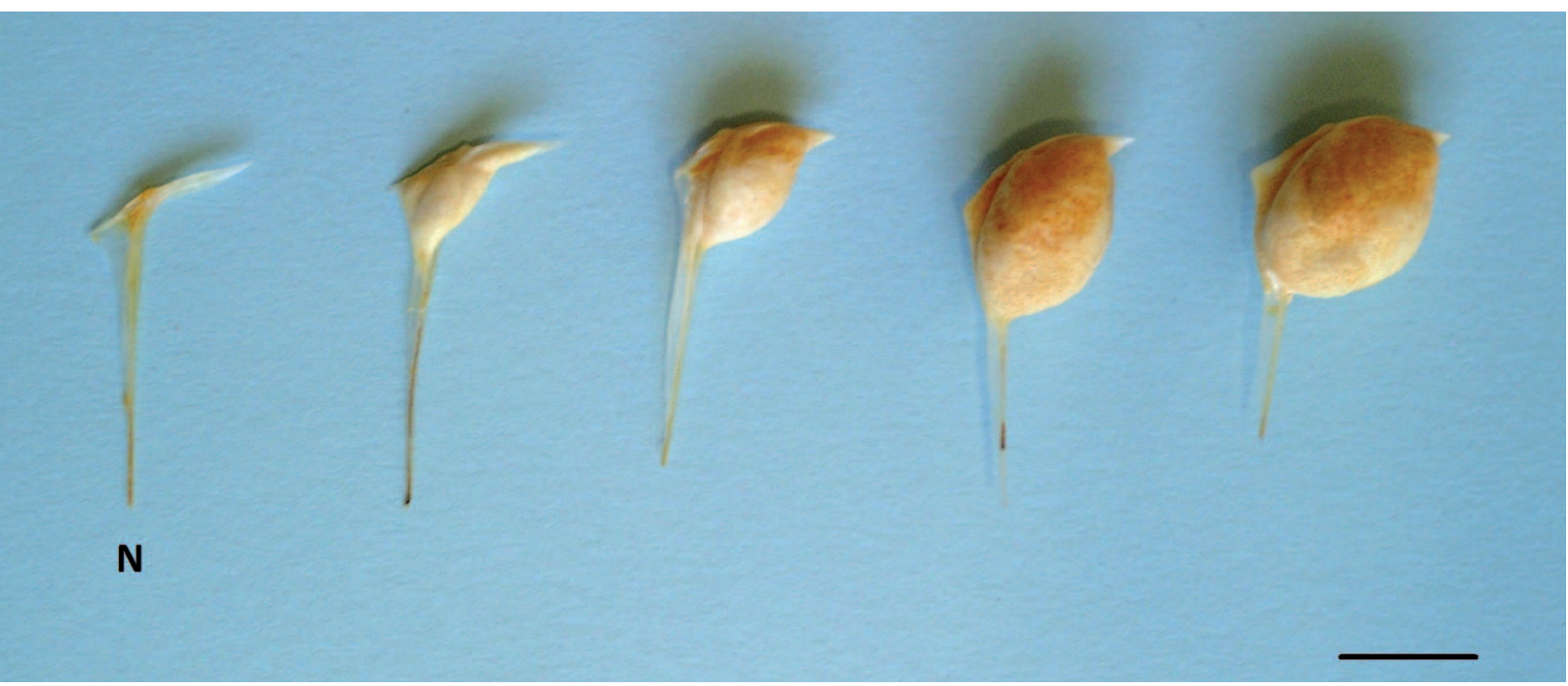

Fig. 3. Isolated hyperostotic pterygiophores in various development stage of silver scabbardfish, Lepidopus caudatus, caught off Sicily, Italy (N: normal pterygiophores, scale bar: $1 \mathrm{~cm}$ )

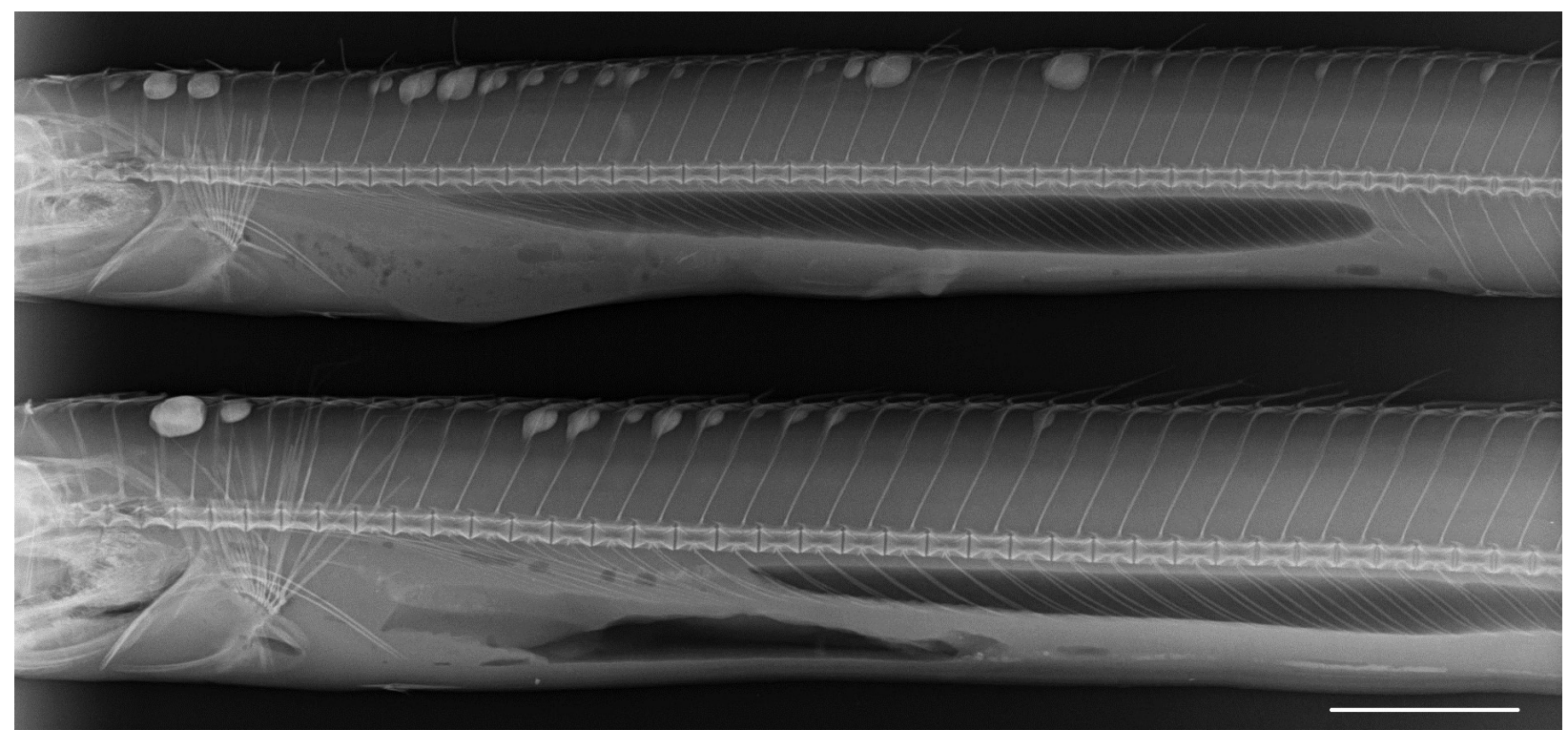

Fig. 4. Radiograph of Lepidopus caudatus exhibiting hyperostotic pterygiophores of silver scabbardfish, Lepidopus caudatus, caught off Sicily, Italy (scale bar: $5 \mathrm{~cm}$ )

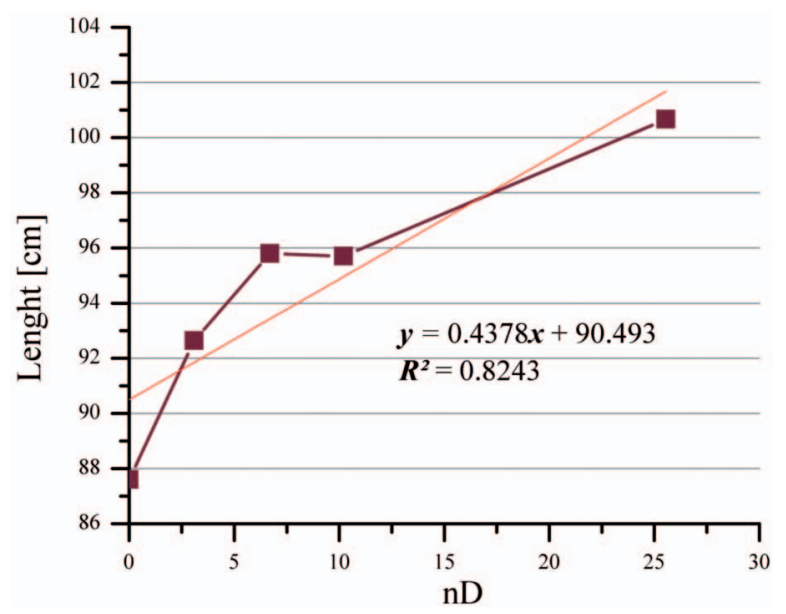

Fig. 5. Statistical correlation between length and number of deformities (nD) of silver scabbardfish, Lepidopus caudatus, caught off Sicily, Italy

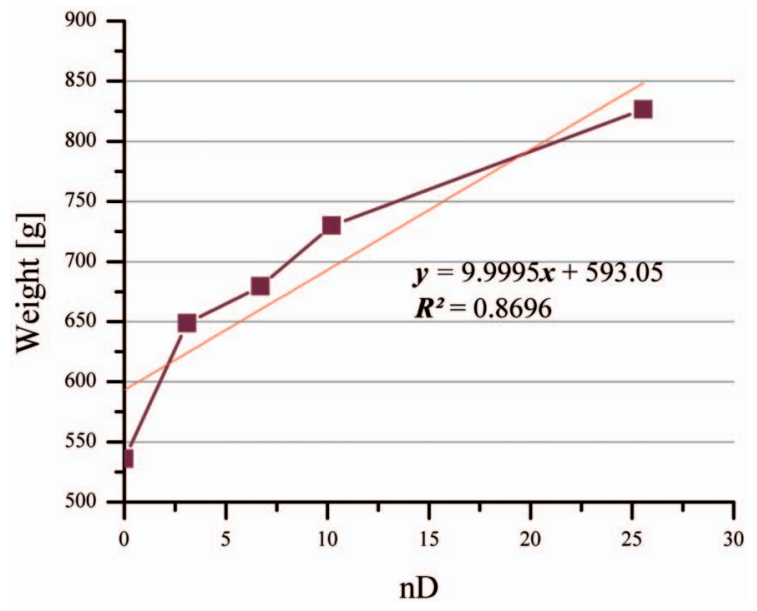

Fig. 6. Statistical correlation between weight and number of deformities (nD) of silver scabbardfish, Lepidopus caudatus, caught off Sicily, Italy 


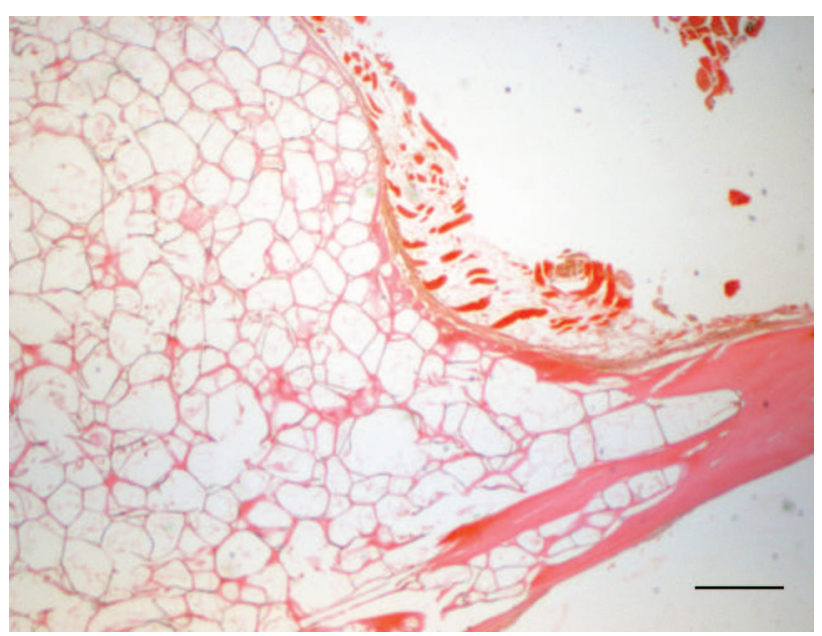

Fig. 7. Histological findings: spongy-like aspect of hyperostotic pterigiophore (HE) of silver scabbardfish, Lepidopus caudatus, caught off Sicily, Italy (scale bar: $400 \mu \mathrm{m})$

\section{DISCUSSION}

Hyperostosis is an important thickening of bone tissue characterised by a swollen appearance. It results from a significant increase in the periosteal ossification of the bones. The spongy-like appearance is caused by an active resorption of the bony tissues (Meunier et al. 2010). Hyperostosis has been reported in several vertebrates, including fish (Capasso 2005), where it has been used by archeoichthyologists as a diagnostic criterion and by taxonomists as a taxonomical tool. In paleopathology, hyperostotic pterygiophores were described in species fossils of trichiurid fishes: L. albyi and L. proargenteus (see Meunier et al. 2010).

Hyperostosis of $L$. caudatus does not affect its consumption. However, it may be a complication for filleting techniques as the presence of hyperostosis along the longitudinal axis of teleosts does not allow a complete and repeatable filleting technique. Due to the presence of hyperostosis, the blade meets, inevitably, additional diverse obstacles along its path, increasing the possibility of bacterial contamination, loss of muscle tissue, and imperfections in cutting and trimming.

Hyperostoses were described for the first time as 'os vormianum' by Worm in 1655 (Schlüter et al. 1992). In 1881 Van Beneden reported hyperostosis in fish bones as a 'corps énigmatiques' (Schlüter et al. 1992), and in 1982, it was described by Grabda (1982) as 'like cystic growths'. For a long time, hyperostosis was considered as an osteoma, a benign bone neoplasm. Among Trichiuridae, the presence of osteomas in Trichiurus lepturus has been reported previously (Lima et al. 2002). Osteomas, which are macroscopically nearly identical to hyperostosis, have been observed in T. lepturus particularly on the haemal and neural spines.

According to some authors, hyperostosis is not a pathological formation (Olsen 1971, Desse et al. 1981, Gauldie and Czochanska 1990). Different hypotheses have proposed that hyperostosis were formed owing to genetic factors, fungal infection, metabolic abnormality, an aid in fin formation or buoyancy, and a reaction to high temperature or water poisoning (Grabda 1982, Greenwood 1992, Schülter and Kohring 2002, Capasso 2005, Meunier et al. 2010) as also reported for other bones deformities (Jawad 2004, Jawad and Hosie 2007). Grabda (1982) suggested a fungal origin of hyperostosis. In fact, he suggested that the outgrowths found on the fin pterygiophores of L. caudatus resulted from infection with yeast-like fungi, probably belonging to the genus Candida. In our case, this hypothesis can be excluded as histologically, no yeastlike fungi were found. Greenwood (1992) as well as Schülter and Kohring (2002) suggested environmental induction as a possible explanation for the occurrence of hyperostosis. In particular, Greenwood (1992) ascribes the presence of hyperostosis in Tilapia guinasana to the high calcium carbonate content in the waters of Lake Guinas (Namibia), while Schülter and Kohring (2002) reported that hyperostosis in fossil cichlids of Lake Manyara (Tanzania) developed due to an excess of fluorine in the water. In both cases, the development of these deformities represents an attempt at detoxification. According to Capasso (2005), hyperostotic bones may represent a biological strategy for fish to adapt to difficult environmental conditions. He also suggested that focal hyperostoses of fish are a result of mechanisms put in place to increase body weight and thus facilitate bottom browsing at shallow depths or swimming in hypersaline waters. In the presently reported study, macroscopic and histological findings suggested that the bone deformities observed on pterygiophores were hyperostoses. Microscopic examination of histological preparations allowed the observation of new bone growth, with proliferation of acellular trabeculae, coated with a thin compact bone layer. Moreover, low cellularity and different sizes observed in these pterygiophores may indicate slow growth and a late onset of individual outbreaks. There was a high incidence $(80 \%)$ of hyperostosis on pterygiophores in the specimens of $L$. caudatus examined. Hyperostotic pterygiophores in this species increased in size and number with the growth of fish, as demonstrated by the correlation found between fish size (fork-length and weight) and the $\mathrm{nD}$ observed. This correlation suggests that the deformities observed in L. caudatus may represent 'a mechanism to increase the body weights and thus facilitate bottom browsing at shallow depths', as hypothesized by Capasso (2005).

\section{REFERENCES}

Capasso L.L. 2005. Antiquity of cancer. International Journal of Cancer 113 (1): 2-13.

DOI: $10.1002 /$ ijc. 20610

Dawson C. 1964. A bibliography of anomalies of fishes. Gulf Research Reports 1 (6): 308-399.

Dawson C. 1966. A bibliography of anomalies of fishes. Gulf Research Reports 2 (1): 169-176. 
Dawson C. 1971. A bibliography of anomalies of fishes. Gulf Research Reports 3 (2): 215-239.

Dawson C., Heal E. 1971. A bibliography of anomalies of fishes. Gulf Research Reports 5 (3): 35-41.

Desse G., Meunier F.J., Peron M., Laroche J. 1981. Hyperostose vertébrale chez l'animal. Rhumatologie 33 (2): 105-119.

Gauldie R.W., Czochanska Z. 1990. Hyperostotic bones from the New Zealand snapper Chrysophys auratus (Sparidae). Fishery Bulletin 88 (1): 201-206.

Grabda E. 1982. Fungi-related outgrowths on pterygophores of single fins of Lepidopus caudatus (Euphrasen, 1788) (Pisces: Trichiuridae). Acta Ichthyologica et Piscatoria 12 (1): $87-103$.

Greenwood P.H. 1992. A redescription of the uniquely polychromatic African cichlid fish Tilapia guinasana Trewavas, 1936. Bullettin of the British Museum (Natural History), Zoology 58 (1): 21-36.

James P.S.B.R. 1960. Instances of excessive thickening of certain bones in the ribbon fish, Trichiurus lepturus Linnaeus. Journal of the Marine Biological Association of India 2 (2): 253-258.

Jawad L.A. 2004. First record of an anomalous mullet fish (Mugil cephalus) from New Zealand. Tuhinga 15: 121-124.

Jawad L.A., Hosie A. 2007. On the record of pug-headedness in snapper, Pagrus auratus (Forster, 1801) (Perciformes, Sparidae) from New Zealand. Acta Adriatica 48 (2): 205-210.

Lima F.C., Souza A.P.M., Mesquita E.F.M., Souza G.N., Chinelli V.C.J. 2002. Osteomas in cutlass fish, Trichiurus lepturus L., from Niteroi, Rio de Janeiro state, Brazil. Journal of Fish Diseases 25 (1): 57-61. DOI: 10.1046/j.1365-2761.2002.00336.x

Meunier F.J., Gaudant J., Bonelli E. 2010. Morphological and histological study of the hyperostoses of Lepidopus albyi (Sauvage, 1870), a fossil Trichiurideae from the Tortonian (Upper Miocene) of Piedmont (Italy). Cybium 34 (3): 293-301.
Olsen S.J. 1971. Swollen bones in the Atlantic cutlassfish, Trichiurus lepturus Linnaeus. Copeia 1971 (1): 174-175. DOI: $10.2307 / 1441623$

Rapisarda G., Macrì F., Manganaro M., Marino F., Mazzullo G., Quaglio F. 2008. Iperostosi in ricciola (Seriola dumerilii) e pagro (Pagrus pagrus). [Hyperostosis in greater amberjack (Seriola dumerilii) and common seabream (Pagrus pagrus).] Ittiopatologia 5: 195-200. [In Italian.]

Schlüter T., Kohring R. 2002. Palaeopathological fish bones from phosphorites of the Lake Manyara area, Norther Tanzania-Fossil evidence of a physiological response to survival in an extreme biocenosis. Environmental Geochemistry and Health 24 (2): 131-140.

DOI: $10.1023 / \mathrm{A}: 1014207530176$

Schlüter T., Kohring R., Mehl J. 1992. Hyperostotic fish bones ('Tilly bones') from presumably Pliocene phosphorites of the Lake Manyara area, Northern Tanzania. Paläontologische Zeitschrift 66 (1-2): 129-136.

Smith-Vaniz W.F., Carpenter K.E. 2007. Review of the crevalle jacks, Caranx hippos complex (Teleostei: Carangidae), with a description of a new species from West Africa. Fishery Bullettin 105 (2): 207-233.

Smith-Vaniz W.F., Kaufman L.S., Glowacki J. 1995. Species-specific patterns of hyperostosis in marine teleost fishes. Marine Biology 121 (4): 573-580.

DOI: $10.1007 / \mathrm{BF} 00349291$

Received: 1 August 2012

Accepted: 29 August 2012

Published electronically: 30 September 2012 